\title{
Electronics Design and System Integration of the ATLAS New Small Wheels
}

\author{
Panagiotis Gkountoumis \\ National Technical University of Athens - Brookhaven National Laboratory
}

On behalf of the ATLAS muon collaboration

IPRD16, 03-06/10/2016, SIENA, ITALY 


\section{Overview}

- Introduction

- New Small Wheel electronics

- On detector placement

- Prototype boards

- Vertical Slice integration

- Summary 


\section{Introduction}




\section{New Small Wheel and trigger plans}

Small Wheels

- Consist of:

- Cathode Strip Chambers (CSC)

- Thin Gap Chambers (TGC)

- Monitor Drift Tube (MDT)

- Not efficient in high rates (maximum $20 \mathrm{KHz} / \mathrm{cm}^{2}$ )

- $90 \%$ of the current End-cap muon triggers are fakes

New Small Wheels

- A set of precision tracking and trigger detectors able to work at high rates

- Will provide online high quality ( $\sigma \theta \sim 1 \mathrm{mrad}$ ) IP pointing segments

- Significant reduction of fake Level-1 muon triggers
Requirements :

- Phase-1 (2019-2020)

- Level-1 accept @ 100 KHz

- Phase-2 (2024-2026)

- One level-0 accept @ $1 \mathrm{MHz}$

- Dual level: Level-0 @ 1MHz \& Level-1 @ $400 \mathrm{KHz}$

- Dual level : Level-0 @ 4MHz \& Level-1 @ $600 \mathrm{KHz}$

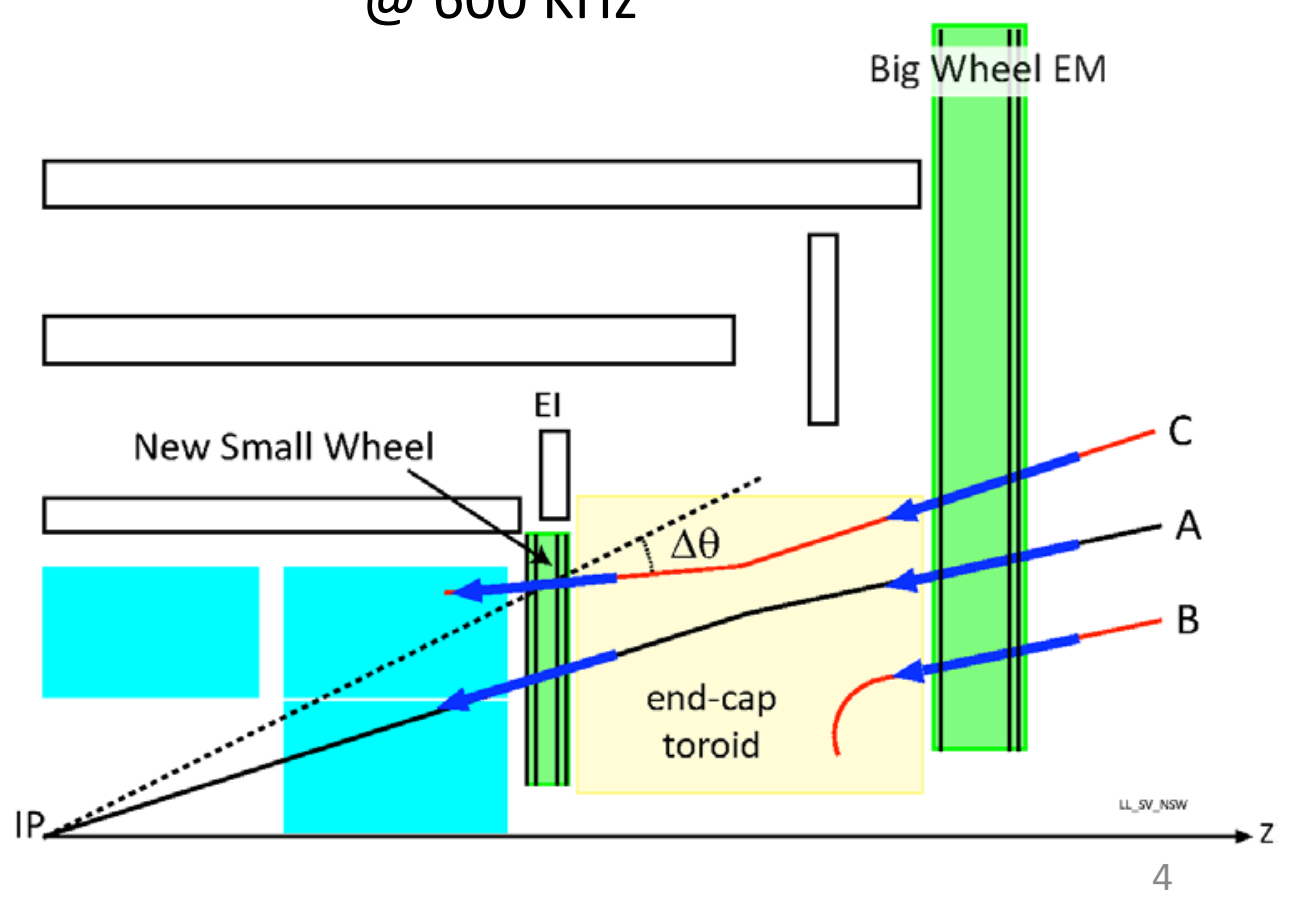


New Small Wheel electronics 


\section{Overall readout and trigger scheme}

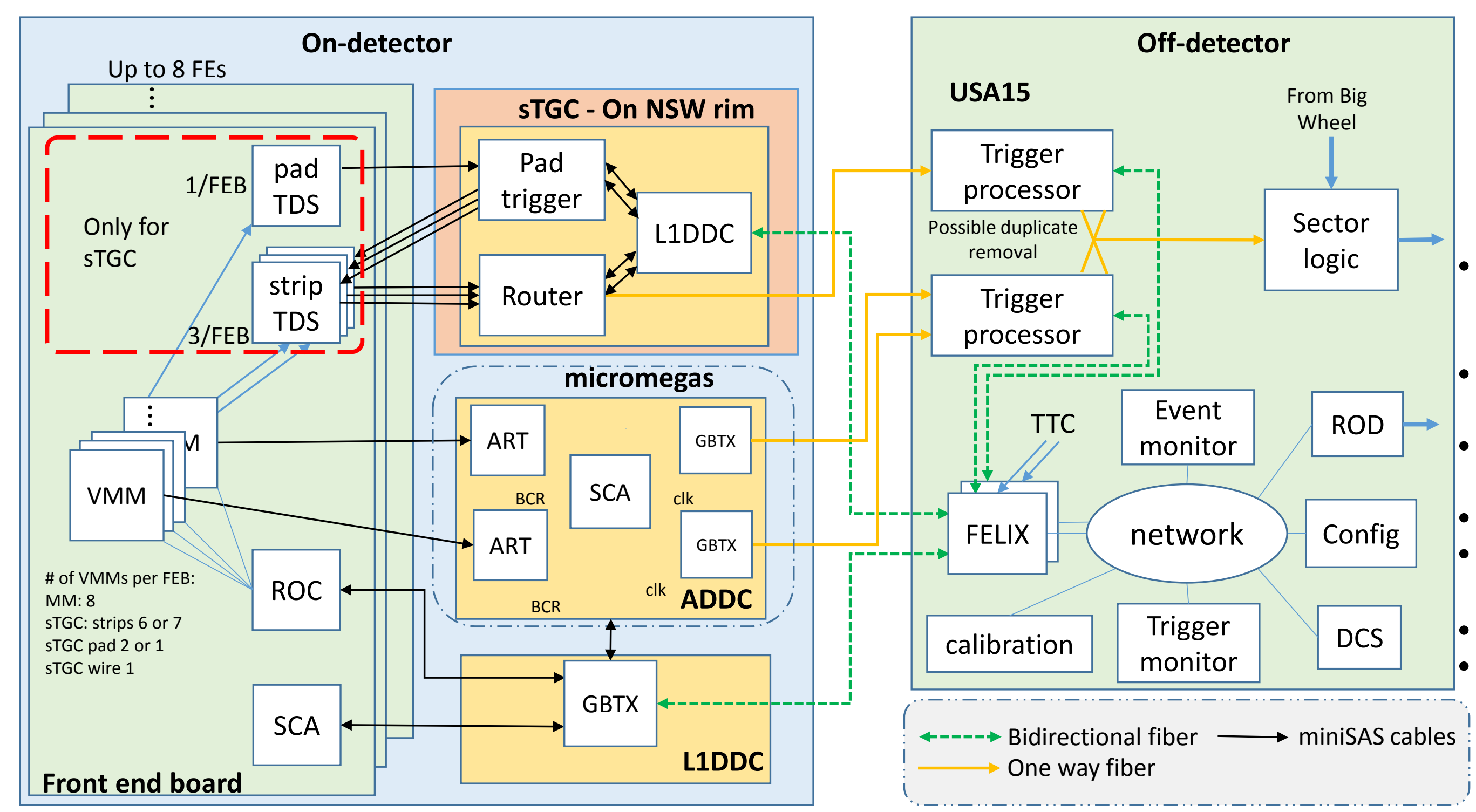

- Radiation tolerant ASICs

Slow Control Adapter (SCA)

- Read Out Controller (ROC)

- $\quad$ Address Real Time (ART)

- GigaBit Transceiver

(GBTX)

- Trigger Data Serializer (TDS)

- VMM (amplifier,

discriminator, shaper)

Front-End LInk eXchange (FELIX) Interface network

- Timing Trigger \& Control (TTC)

Art Data Driver Card (ADDC)

Read Out Device (ROD)

- Detector Control System (DCS)

Front-ends (FE)

Pad trigger and router use commercial FPGAs 


\section{sTGC trigger scheme}

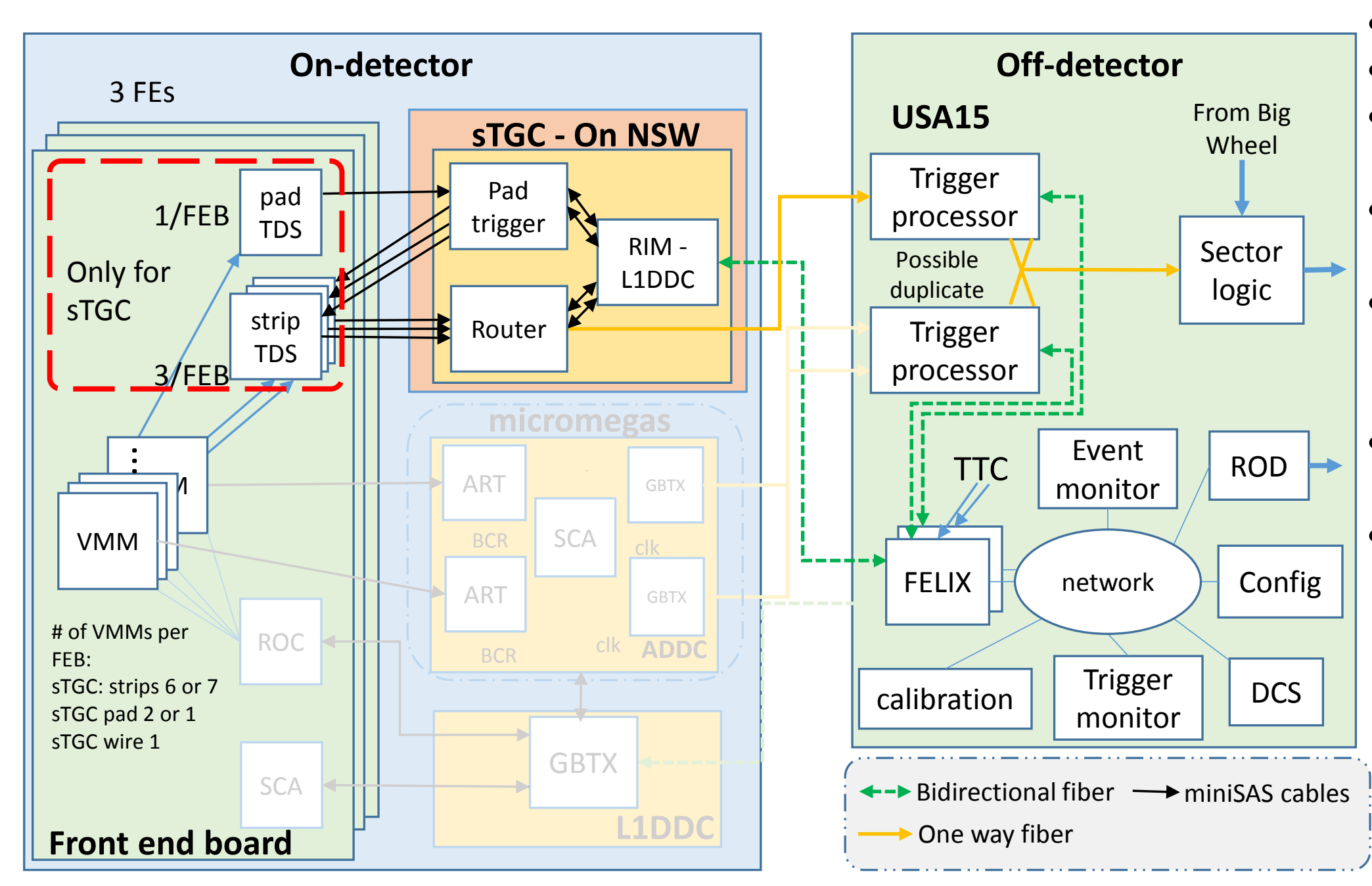

- Time \& amplitude are sent to the pTDS

- Strips are buffered and tagged with the BCID

- Pad trigger logic identifies a track

- The candidate geometrical coordinates \& corresponding BCID are sent to sTDS

- sTDS transmits the strip charges, BCID, band-ID, and $\phi$-ID

- Signals are sent to track finding processors where centroids and track segments are calculated

- Finally, sector logic combines data with candidate tracks from the Big Wheel

- RIM-L1DDC for configuration of the RIM electronics

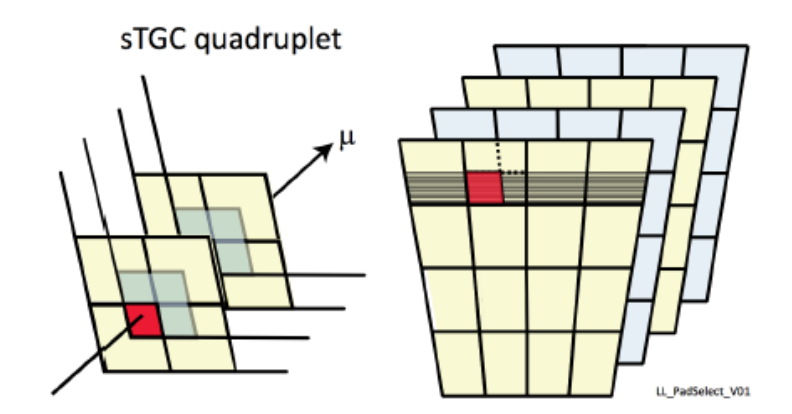

Find a segment - search for the strip only at this segment 


\section{On detector placement}




\section{Electronic board placement on MM detectors}

- FEs will be placed radially on both sides of each plane

- LIDDC and ADDC boards will be placed only on the $1^{\text {st }}$ and $4^{\text {th }}$ plane of each wedge (4 planes)

- 1 LIDDC \& 1 ADDC will serve the 8 FE located on each side of a plane and will be placed on the center to minimize the cable length

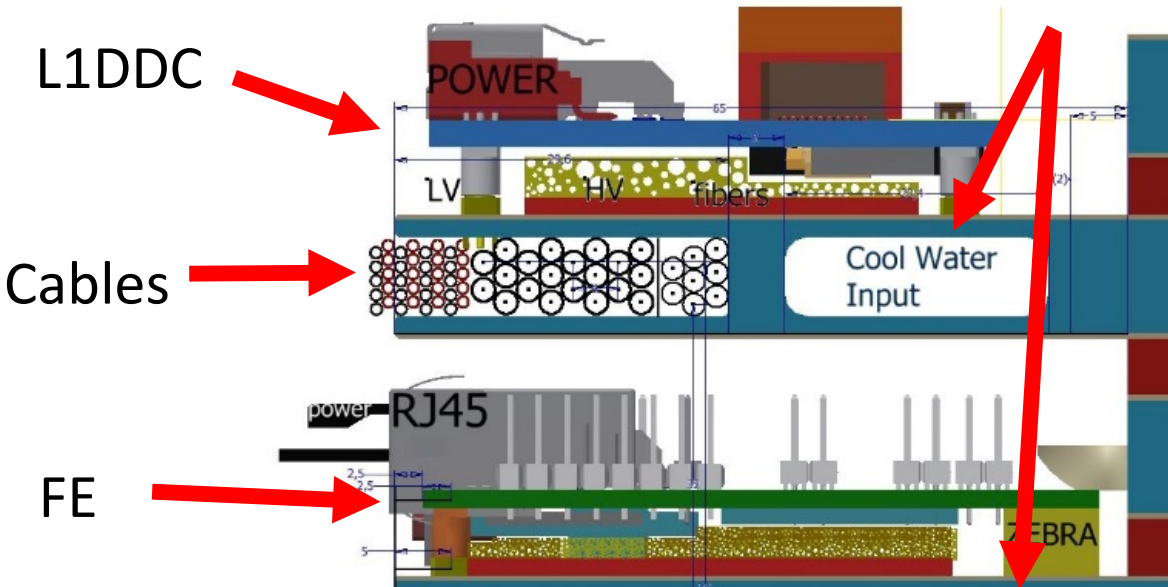

- 512 L1DDC

- 512 ADDC

- 4096 MMFE8

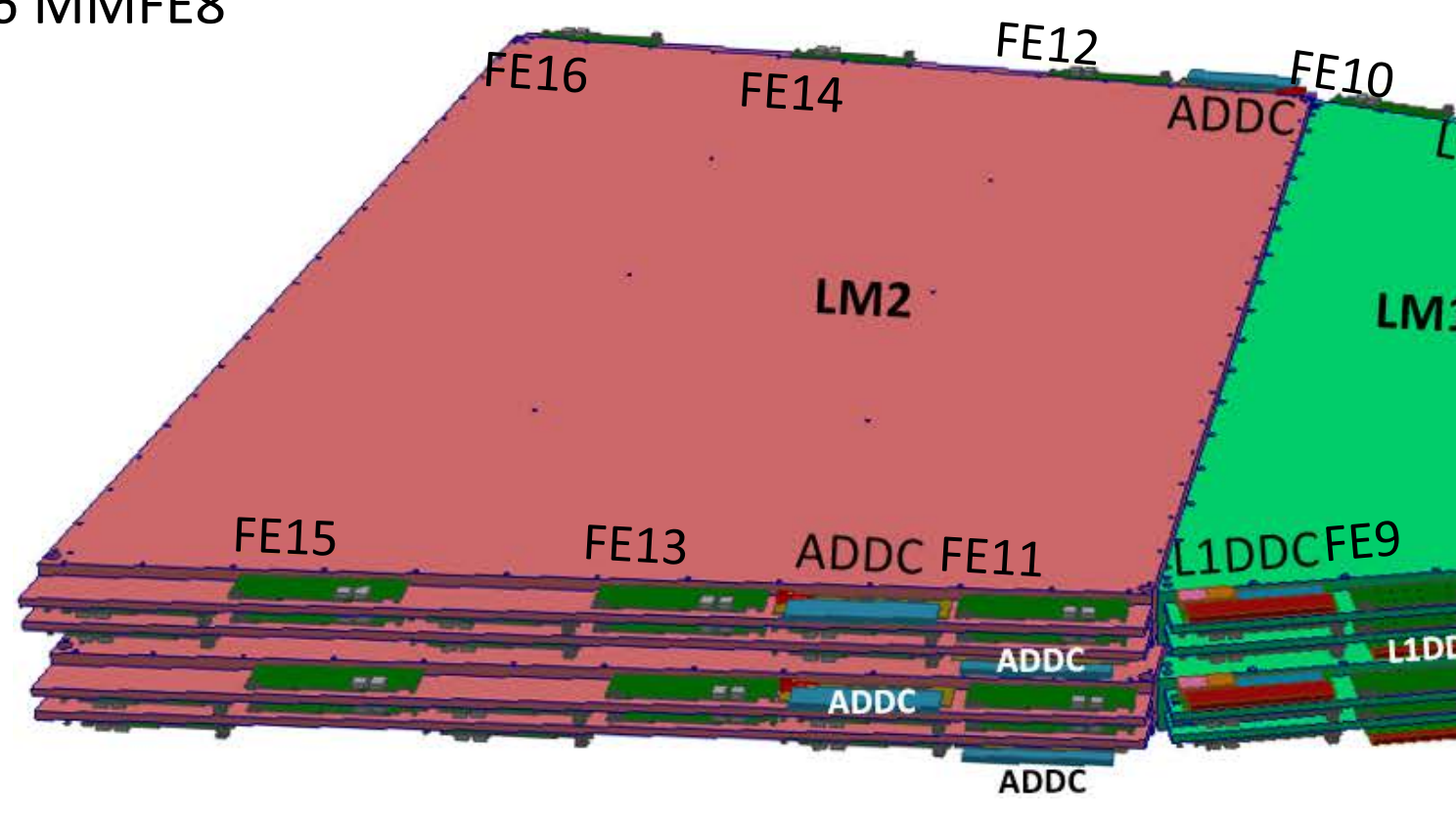




\section{Electronic board placement on sTGC detectors}

- FEs radially on both sides of each plane

- Faraday cage will be used for the STGC FE to isolate the sensitive electronics

- L1DDC will be placed on the upper part close to the rim for accessibility reasons

- 1 L1DDC will serve 3 front ends of each plane

- $768 \mathrm{sFE}$

- 768 p\&wFE

- 512 L1DDC

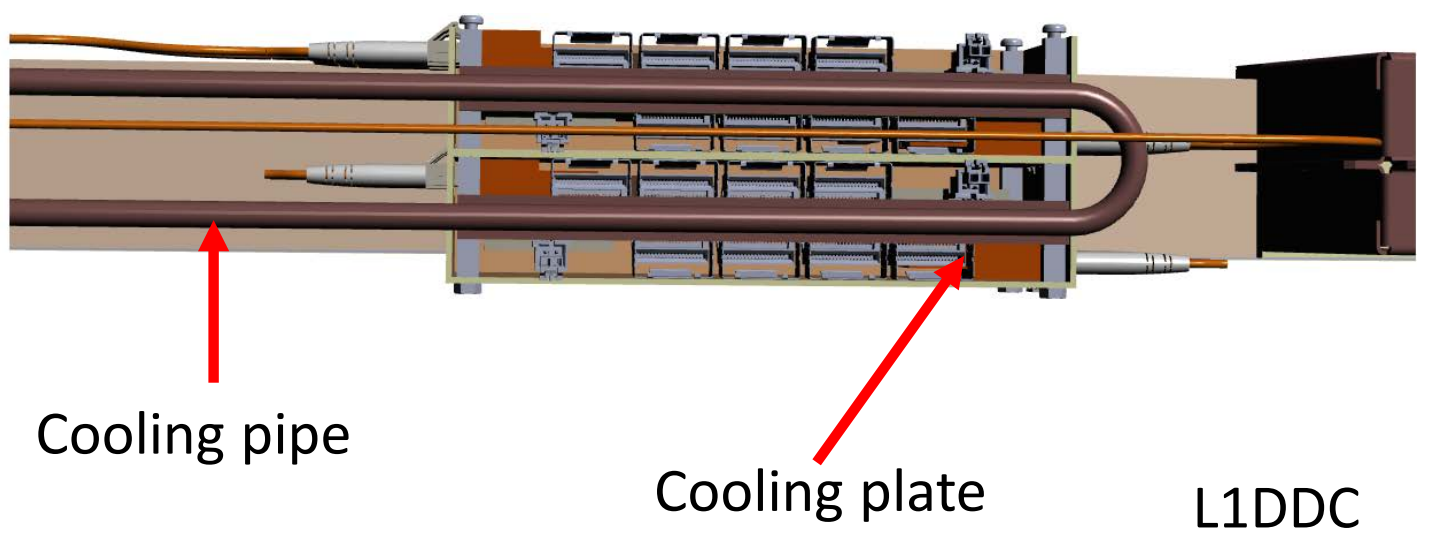




\section{Rim electronics}

- 1 RIM box per sector

- Commercial boxes and electronics will be used

- 32 RIM-L1DDC

- 32 PAD trigger

- 256 Routers
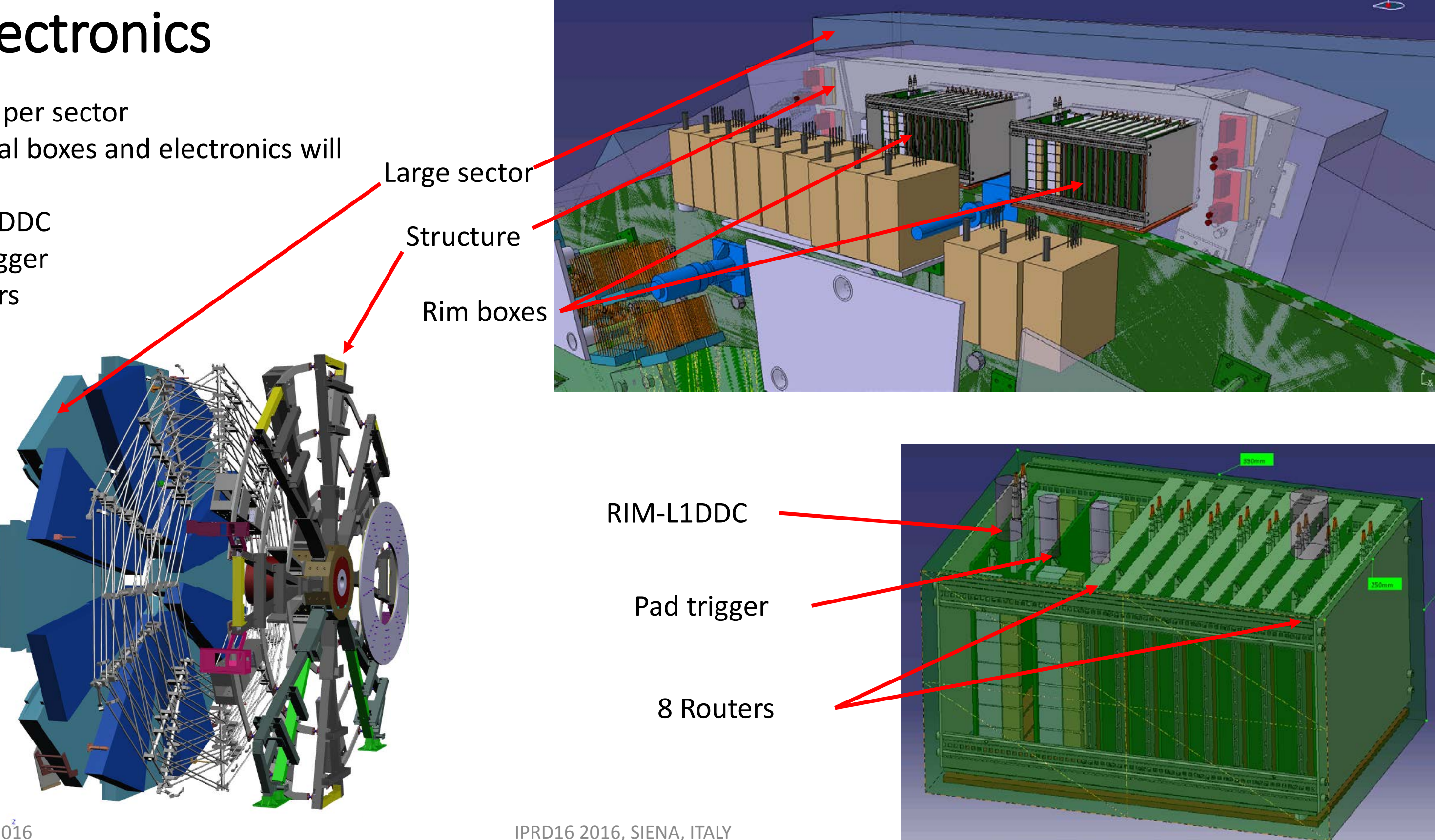


\section{Prototype boards}




\section{New prototypes}

\section{- MMFE8}

- New prototype using radiation tolerant DC-DC converters is already fabricated and under testing

- Next prototype with VMM3 will be submitted this month

- L1DDC

- Fabrication of 10 boards this month

- $\mathrm{ADDC}$

- Schedule for prototype-2 when ART ASIC is tested

- LIDDC and ADDC new prototypes will use only radiation and magnetic tolerant components based on final requirements (dimensions, rate, components)

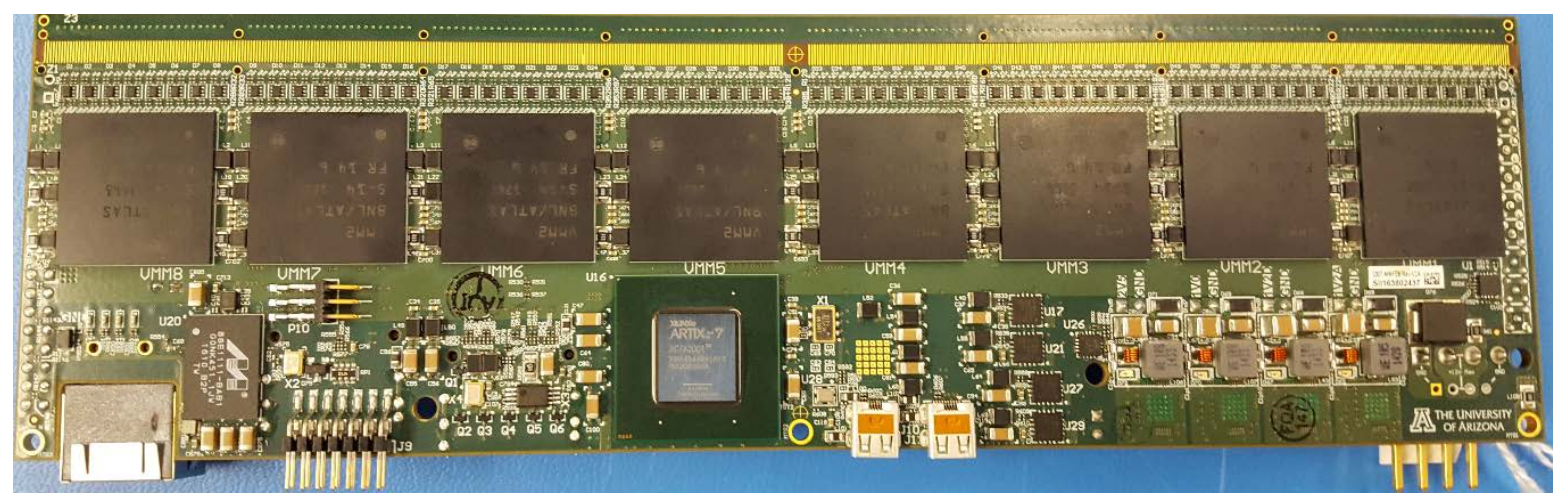

L1DDC prototype-2 for MM detectors

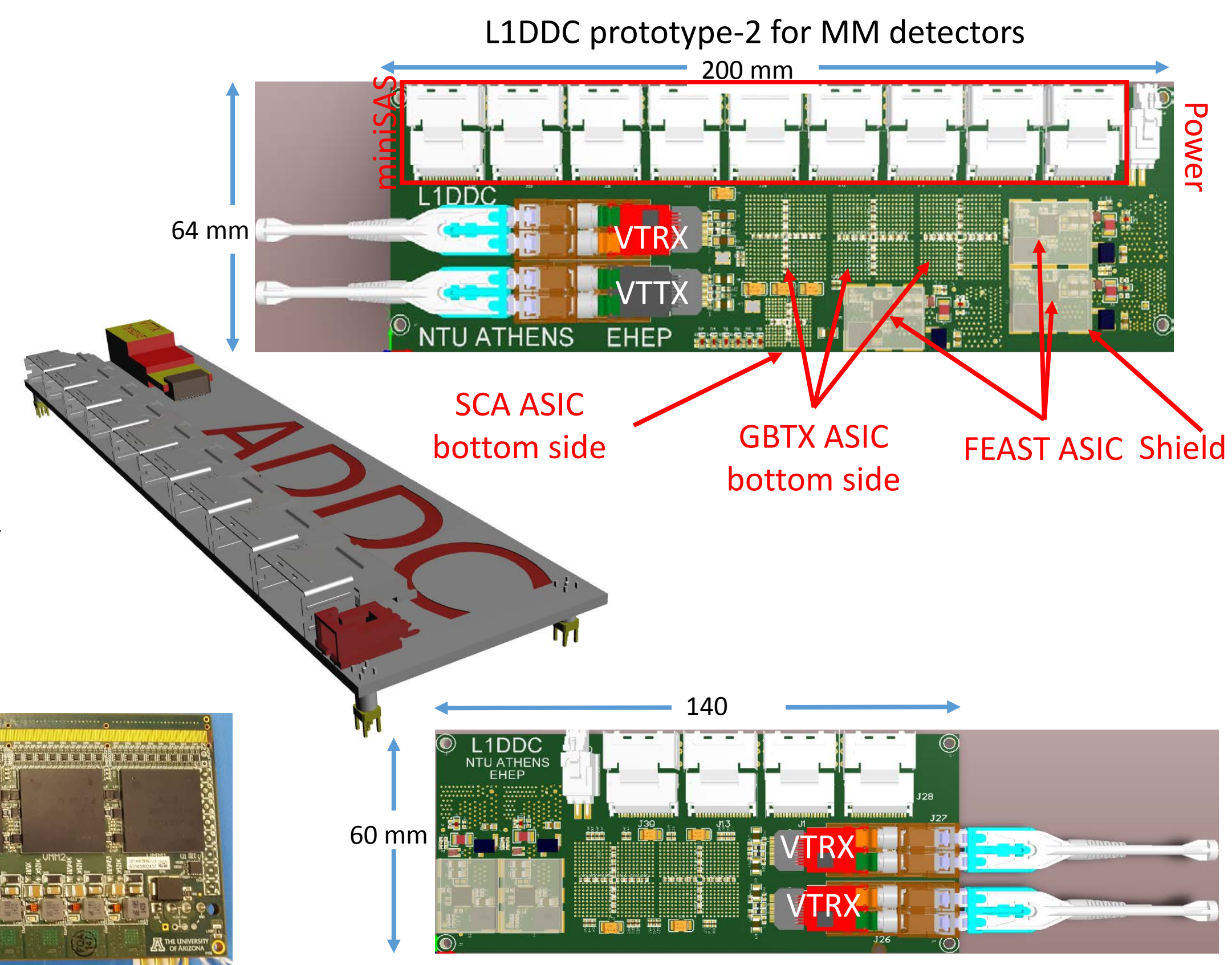




\section{Vertical slice integration}




\section{Vertical Slice integration week}

- Allocated a space in building 188 at CERN for the NSW electronics

- 8-14 of August mainly focused on MM (data + trigger)

- 15-21 of August mainly focused on sTGC (data)

- People from Arizona, NTUA/BNL, Harvard, USTC, McGill, Carleton, Irvine, Avans
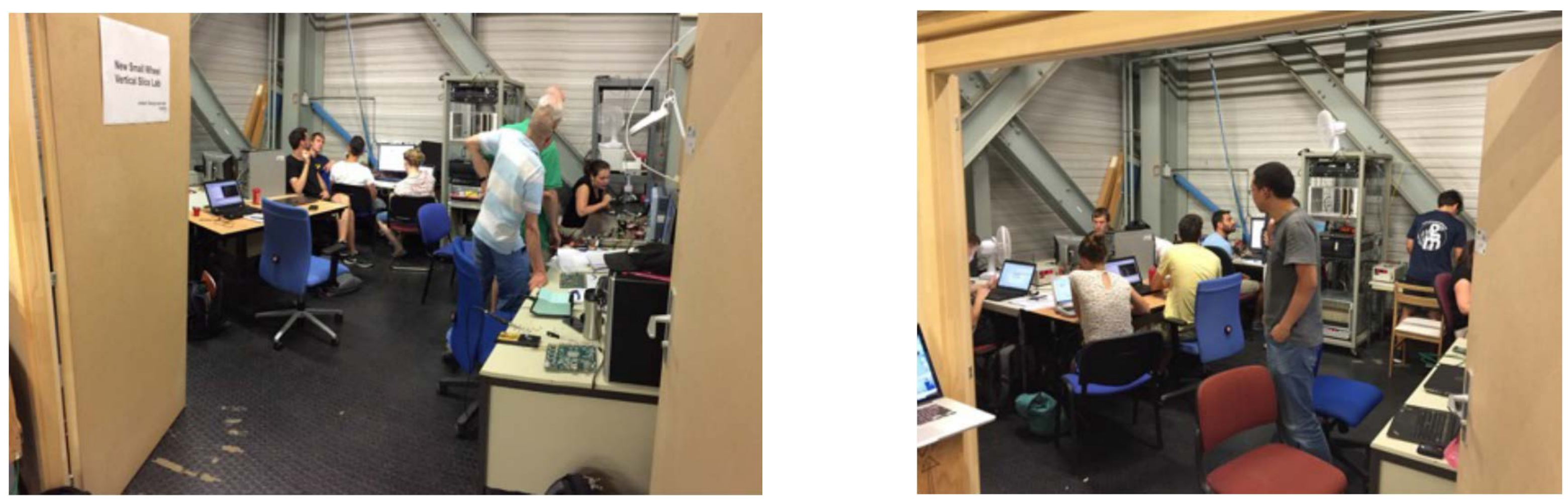


\section{What was achieved}

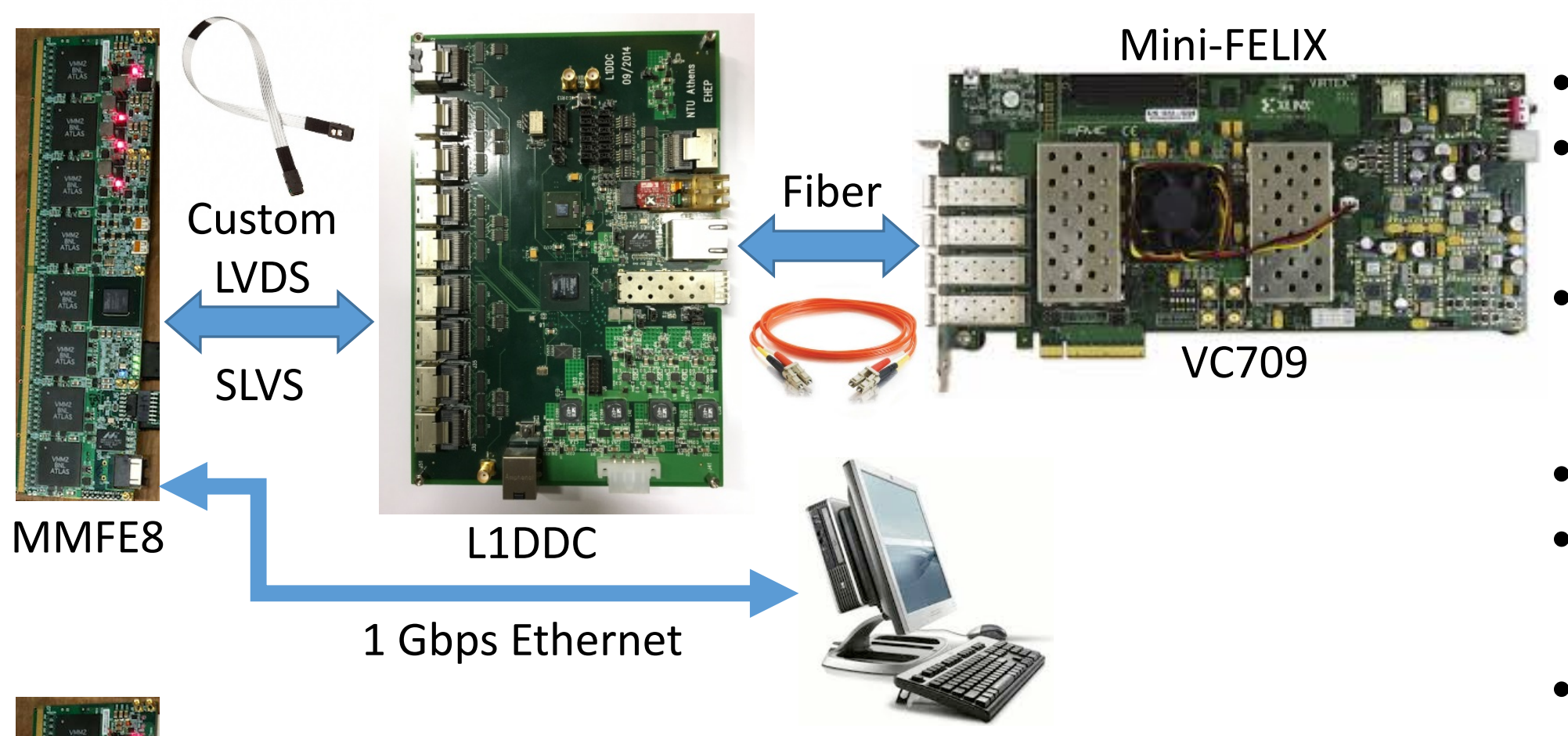

MMFE8 readout firmware $\checkmark$

- MMFE8 communication with the Software (UDP protocol over 1Gbps Ethernet) $\sqrt{ }$

- MMFE8 communication with the L1DDC @ 80 Mbps $\sqrt{ }$

- Link of L1DDC with FELIX established $\sqrt{ }$

- MMFE8, ADDC and trigger processor was also established $\sqrt{ }$

- Twinax cables, communication standards (custom LVDS, SLVS) and grounding schemes

Custom LVDS

Twinax MMFE8 cable

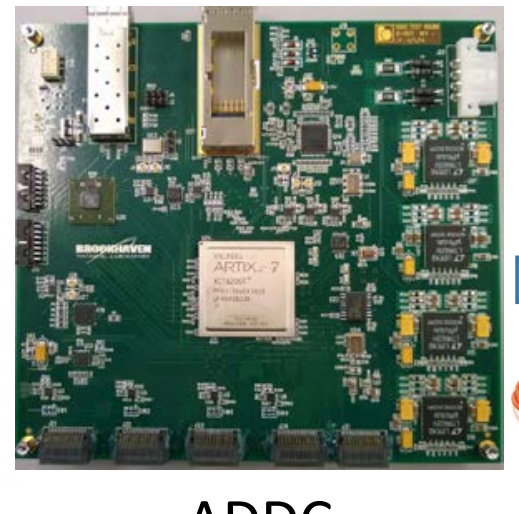

ADDC

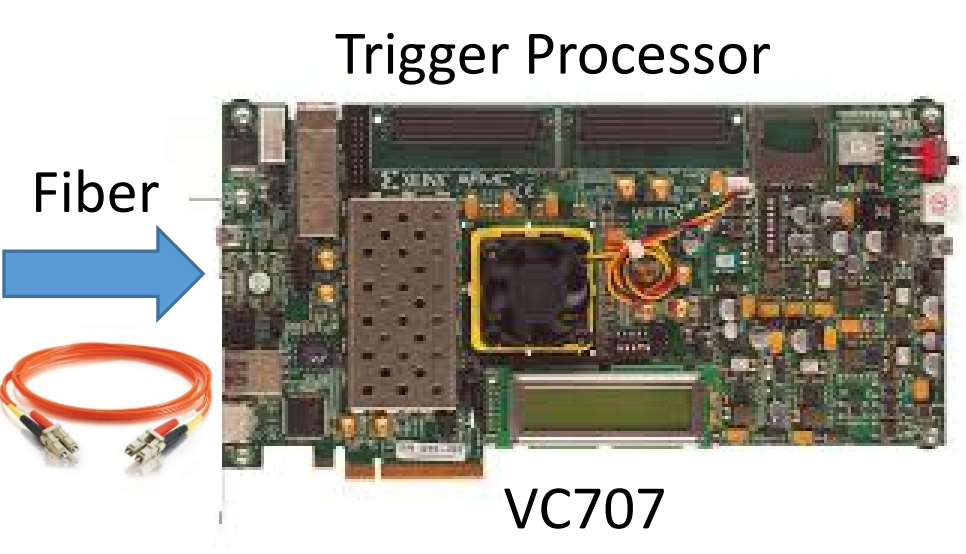

VC707

IPRD16 2016, SIENA, ITALY 


\section{Summary}

- NSW electronics will be able to cope with the high data rates of the HL-LHC

- On detector electronics will use only radiation and magnetic tolerant components

- 3D simulations can confirm that the electronics can fit nicely on the chambers

- The two "integration weeks" were very useful for starting and achieving the integration of NSW electronics

- Integration week proved that the goal is achievable

- A lot of work still need to be done - looking forward to the next integration week 


\section{References}

\section{ASICS}

- GBT project: https://espace.cern.ch/GBT-Project/default.aspx

- GBTX: https://espace.cern.ch/GBT-Project/GBTX/Manuals/gbtxManual.pdf

- GBT-SCA: https://espace.cern.ch/GBT-Project/GBT-SCA/Manuals/GBT-SCA Manual V8.0.pdf

- FEAST: http://project-dcdc.web.cern.ch/project-dcdc/public/Documents/FEAST\%20datasheet.pdf

- GBLD: https://espace.cern.ch/GBT-Project/GBLD/Manuals/GBLDv4 Test Report-October2015.pdf

- VMM: https://twiki.cern.ch/twiki/pub/Atlas/NSWelectronics/vmmSpecification.pdf

- ROC: https://twiki.cern.ch/twiki/pub/Atlas/NSWelectronics/VMM3 ROCspec.pdf

\section{Boards}

- L1DDC design review: https://twiki.cern.ch/twiki/pub/Atlas/NSWParameterBook/MM Parameters.xlsX

- RIM-L1DDC: https://twiki.cern.ch/twiki/pub/Atlas/RimElectronics/RIM GBT.docx

\section{Parameter books}

- sTGC: https://twiki.cern.ch/twiki/pub/Atlas/NSWParameterBook/sTGC.xlsm

- MMs: https://twiki.cern.ch/twiki/pub/Atlas/NSWParameterBook/MM Parameters.xlsx 


\section{Thank you for your attendance!}




\section{Back up slides}




\section{The ATLAS experiment}

On detector electronics

- Mainly custom ASICs will be used - Radiation and magnetic fields

Off detector electronics

- Placed in USA15

- No radiation or magnetic field - commercial electronics will be used

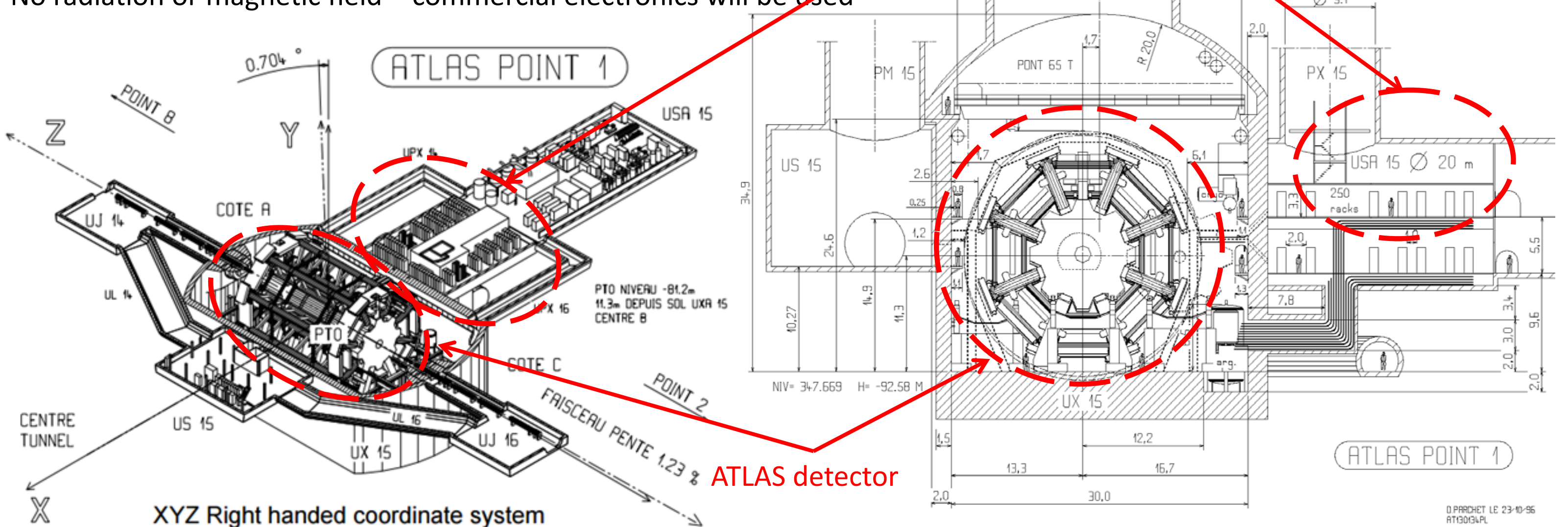
with $\mathrm{z}$ in beam direction 


\section{Radiation tolerant components}

\section{VMM}

- V2 available since 2014 and well tested

- V3 submitted and will be available at the end of this year"

- layout size $13.5 \times 8.4 \mathrm{~mm}^{2}$

- transistor count $\sim 5$ million

- Supply voltage: $1.2 \mathrm{~V}$

- Designed and fabricated using the 130nm 8-metal CMOS technology from IBM

- The ASIC is packaged in a custom $21 \times 21 \mathrm{~mm}^{2} 400$ - pin BGA package

- $600 \mathrm{mV}$ baseline and +/- $150 \mathrm{mV}$ swing

- Power consumption 500-800 mW

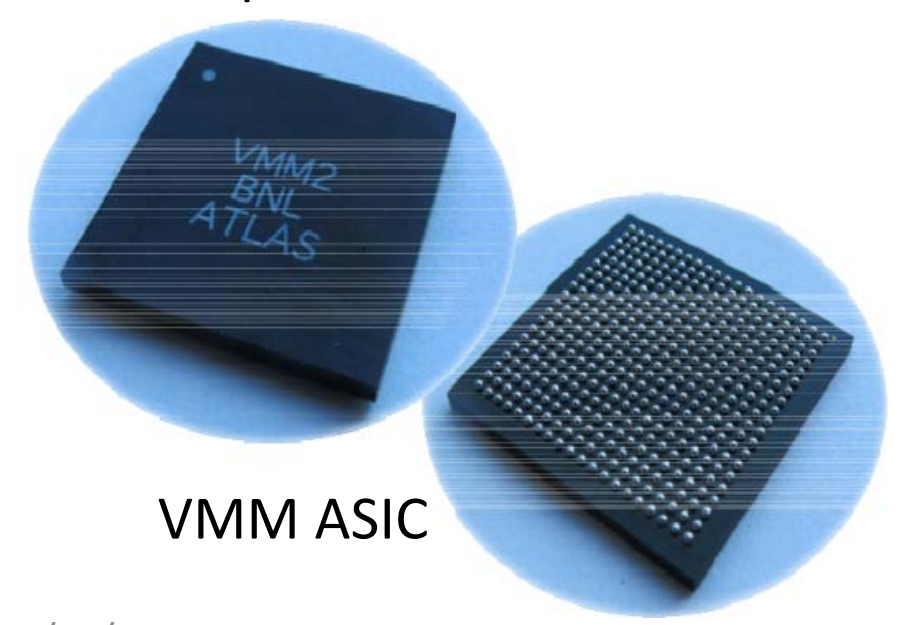

- Fabricated in IBM $130 \mathrm{~nm}$ CMOS technology

- Total area of $20 \mathrm{~mm}^{2}$

- Was submitted for fabrication at $15 / 08 / 2016$

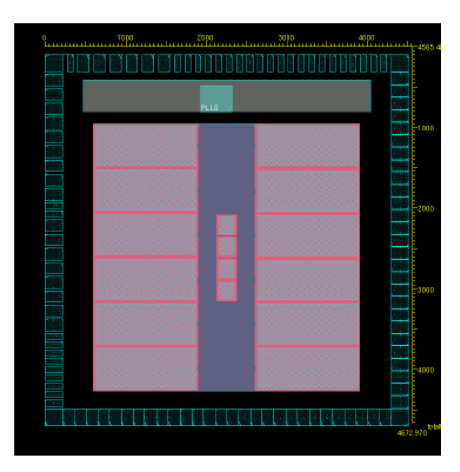

ROC ASIC
TDS

- Power supply $1.5 \mathrm{~V}$

- 400 pin BGA

- Serial output $4.8 \mathrm{Gbps}$

- SLVS for differential and $1.5 \mathrm{~V}$ CMOS for single-ended

- Power consumption 1 A

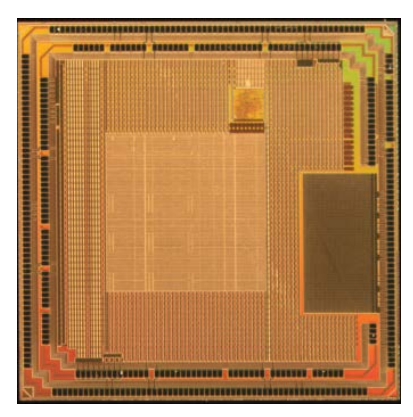

TDS ASIC (die) 


\section{Radiation tolerant components}

\section{GBTX ASIC}

- Is using the IBM/GlobalFoundries $130 \mathrm{~nm}$ CMOS technology

- A serializer/deserializer

- Power supply @1.5V

- Power consumption is $2.2 \mathrm{~W}$ (full operation)

- E-Links use Scalable Low-Voltage Signalling (SLVS) for 400mV (SLVS-400)

VTRX optical transceiver (consists of 2 ASICS)

- The GigaBit TransImpendance Amplifier (GBTIA)

- Bit rate of $5 \mathrm{Gbps}$ (min)

- Total jitter $<40$ ps

- Supply voltage: $2.5 \mathrm{~V}$

- Power consumption: $250 \mathrm{~mW}$

VTRX vs SFP

- GigaBit Laser Diode (GBLD)

- Bit rate of $5 \mathrm{Gbps}$ ( $\mathrm{min}$ )

- Supply voltage: $2.5 \mathrm{~V}$

- Power consumption: $325 \mathrm{~mW}$

VTTX
- $45.3 \mathrm{~mm} * 14: 5 \mathrm{~mm} * 10 \mathrm{~mm}(\mathrm{w} * \mathrm{I} * \mathrm{~h})$

\section{FEAST ASIC}

- Input voltage range 5 to $12 \mathrm{~V}$

- Minimum output voltage $0.6 \mathrm{~V}$

- Continuous 4A load capability

- Very low output noise (Low Drop Out regulators will not be used)

- Adjustable switching frequency 1-3 $\mathrm{MHz}$

- Radiation and magnetic tolerant:
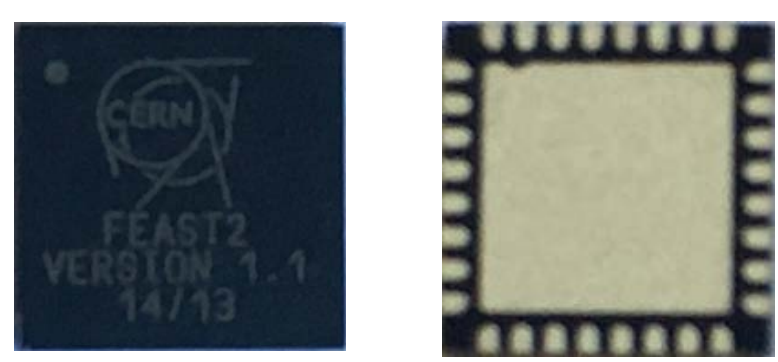

FEAST ASIC

\section{GBT-SCA ASIC}

- Supply voltage: $1.5 \mathrm{~V}$ or $1.2 \mathrm{~V}$

- Package Type: LFBGA

- 0.8 Pitch

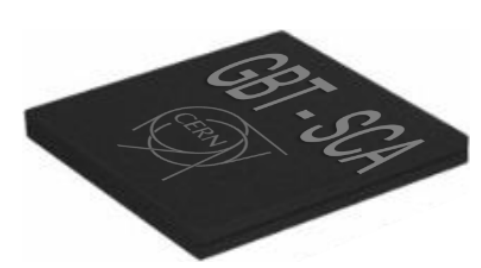

GBT-SCA ASIC

- Pin count 196

- Ball size $0.5 \mathrm{~mm}$ 


\section{VMM Architecture}

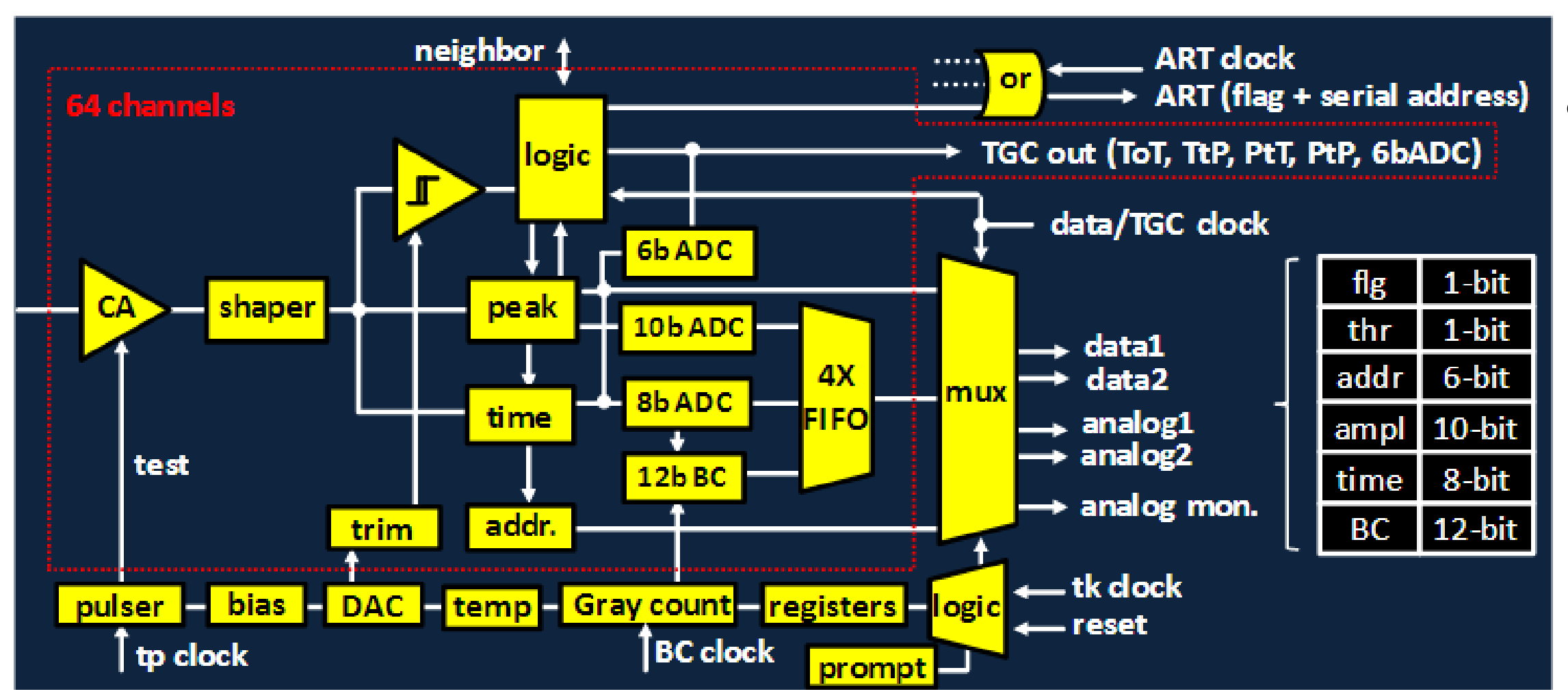

- Is designed to be used with the resistive strip micromegas and sTGC

- It integrates 64 channels, each providing:

- charge amplification

- Discrimination

- neighbor logic

- amplitude and timing measurements

- analog-to-digital conversions

- either direct output for trigger or multiplexed readout. 


\section{ROC Architecture}

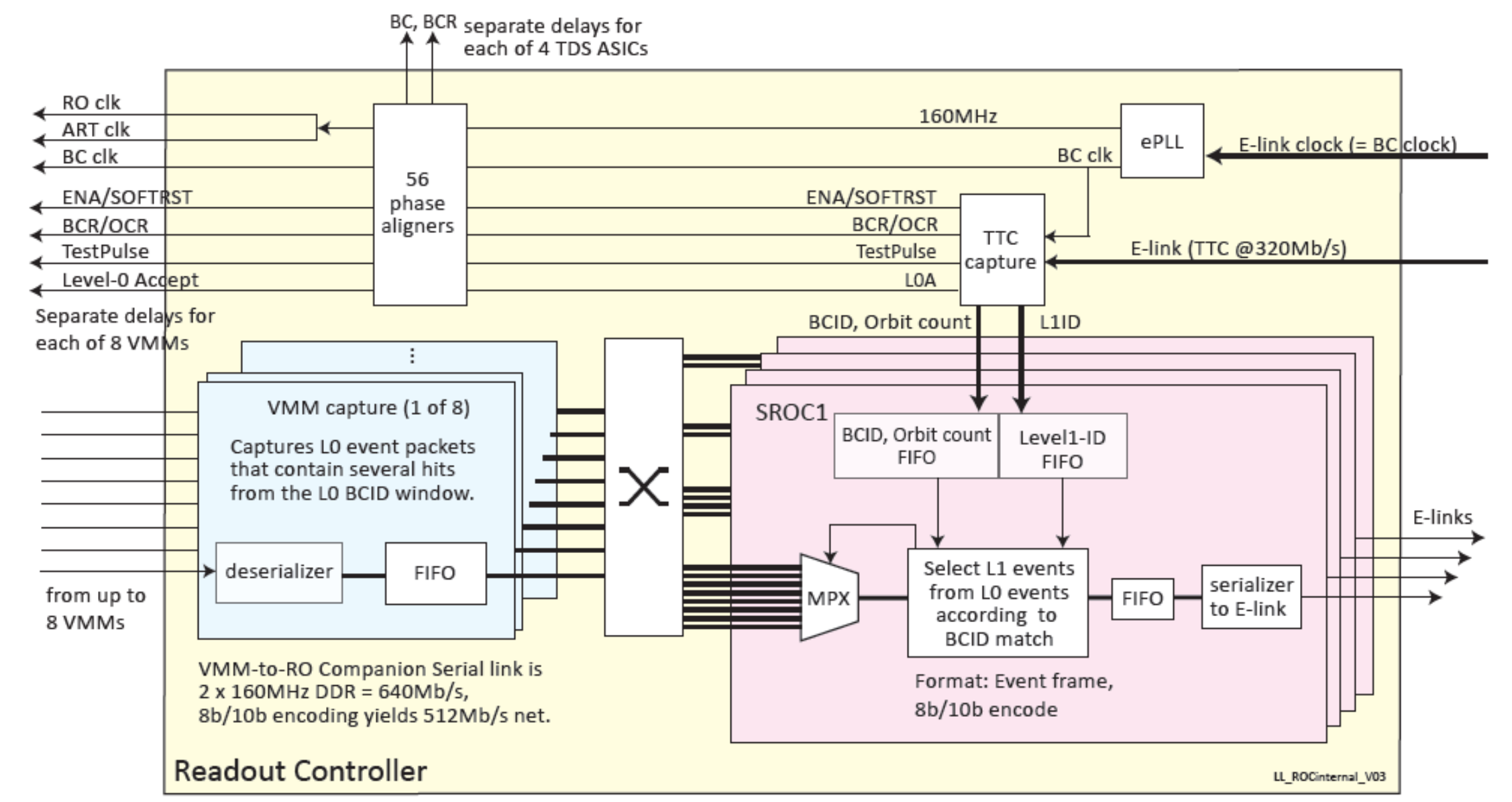

- Merges hits from up to eight VMMs, aggregates, adds headers, process and reformats the data generated by the VMM front-end chips

- Interfaces with up to 4 E-Links @ 320 Mbps or with up to 8 E-Links @ $640 \mathrm{Mbps}$

- For phase two (2 level trigger) ROC buffers the Level-0 accepted events until the arrival of a Level-1 trigger 


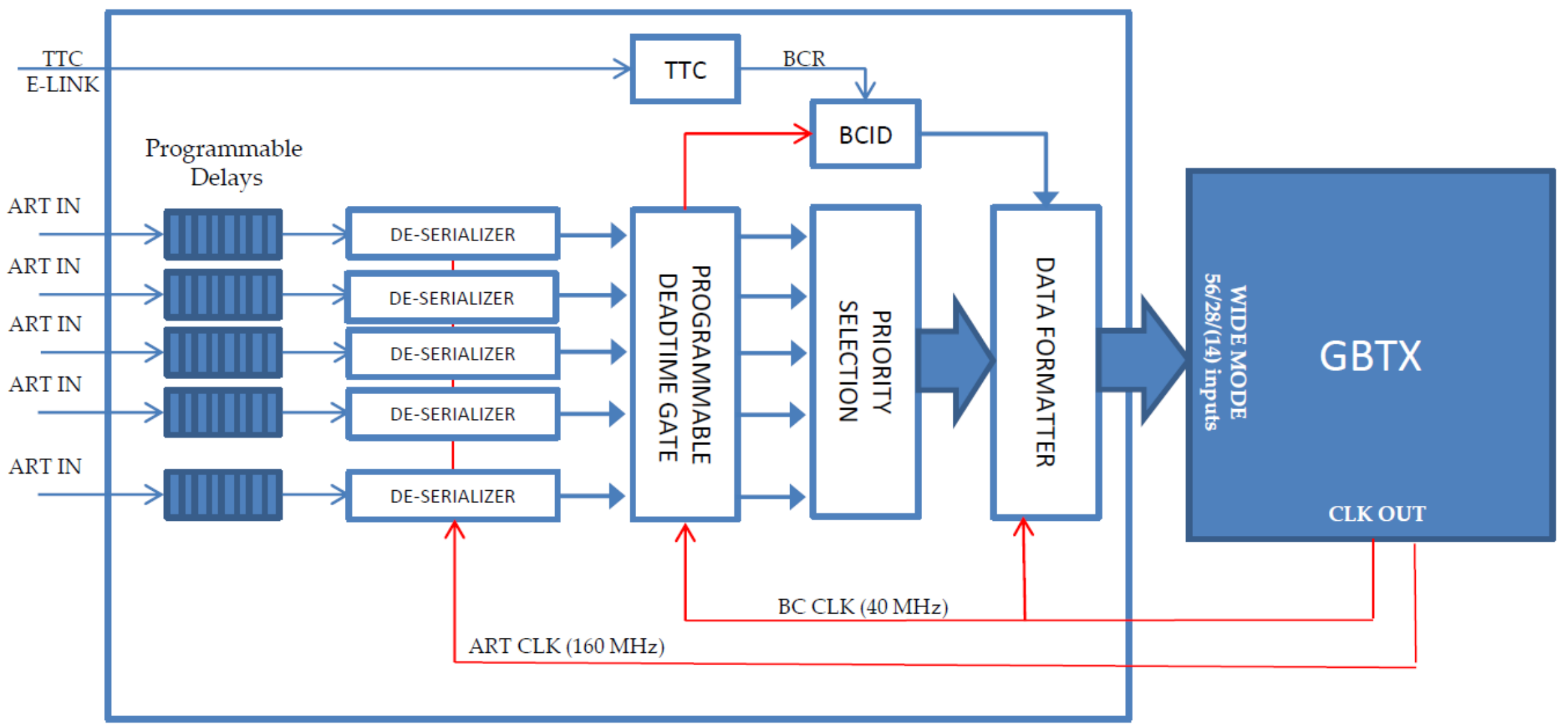

\begin{tabular}{|l|l|}
\hline Block & Description \\
\hline $\begin{array}{l}\text { Programmable } \\
\text { Delays }\end{array}$ & $\begin{array}{l}\text { Adjust input signal phase to avoid FF } \\
\text { violations due to delay on cables }\end{array}$ \\
\hline $\begin{array}{l}\text { ART De- } \\
\text { Serializers }\end{array}$ & Recover 6-bit ART data from ART stream \\
\hline $\begin{array}{l}\text { Programmable } \\
\text { Deadtime Gate }\end{array}$ & $\begin{array}{l}\text { Temporarily (few BC) mask VMM channels } \\
\text { after a hit. }\end{array}$ \\
\hline
\end{tabular}

\begin{tabular}{|l|l|}
\hline Block & Description \\
\hline Hit Selection & $\begin{array}{l}\text { Priority-based hit selection. Selects up to } \\
8 \text { hits from } 32 .\end{array}$ \\
\hline TTC Block & Recover BCR from TTC stream \\
\hline BCID Counter & Generate internal BCID \\
\hline Output Format & Format data for GBTx transmission \\
\hline
\end{tabular}




\section{TDS Architecture}

- Trigger Data Serialiser (TDS) ASICs are required to prepare trigger data for both sTGC pads and strips

- Two modes (selected by hardware pin)

- Strip-TDS

- Pad-TDS

- Performs pad-strip matching

- Serialize trigger data to the rim electronics (4.8 Gbps

Bandwidth)

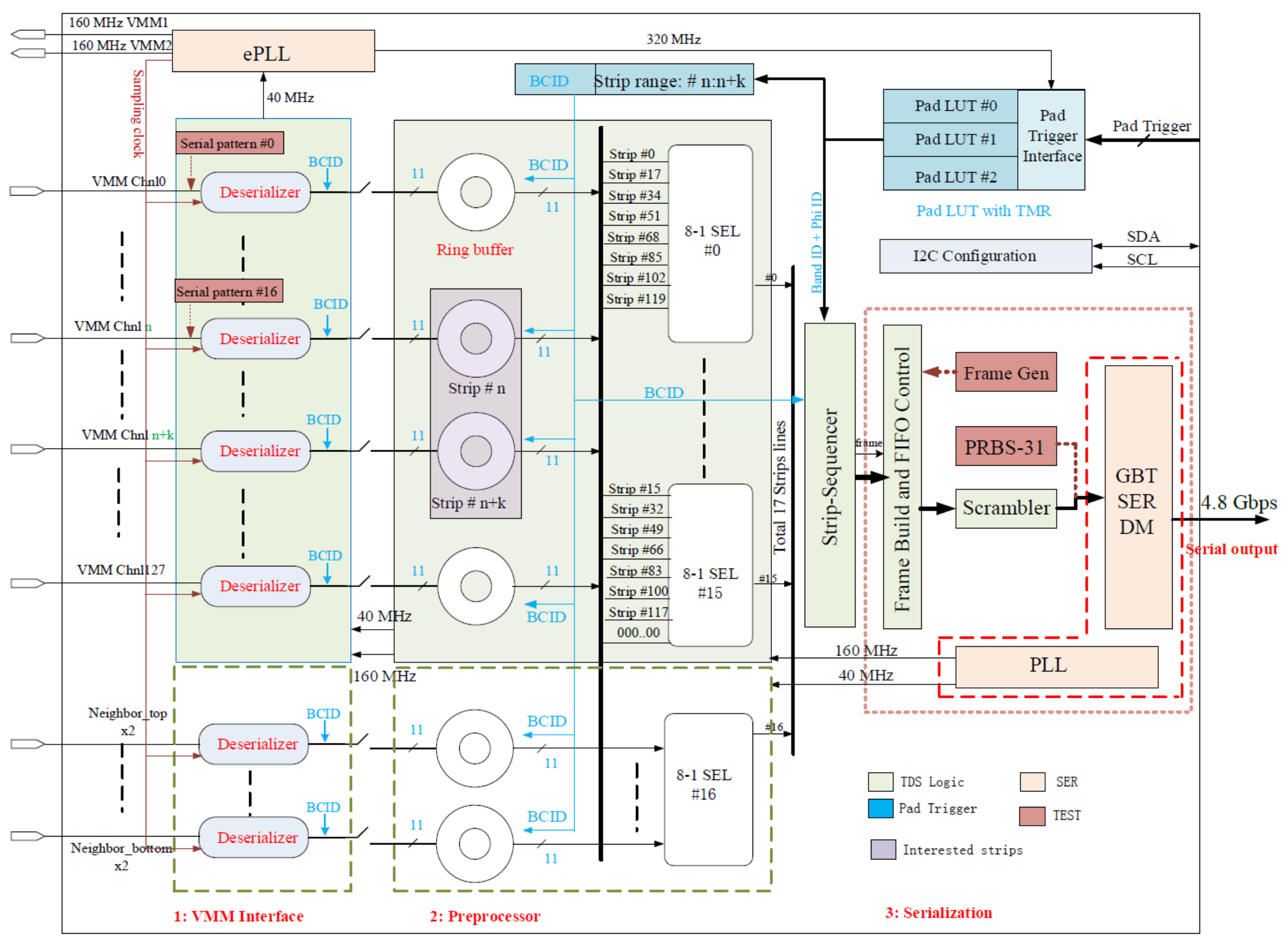




\section{GBTX ASIC architecture}

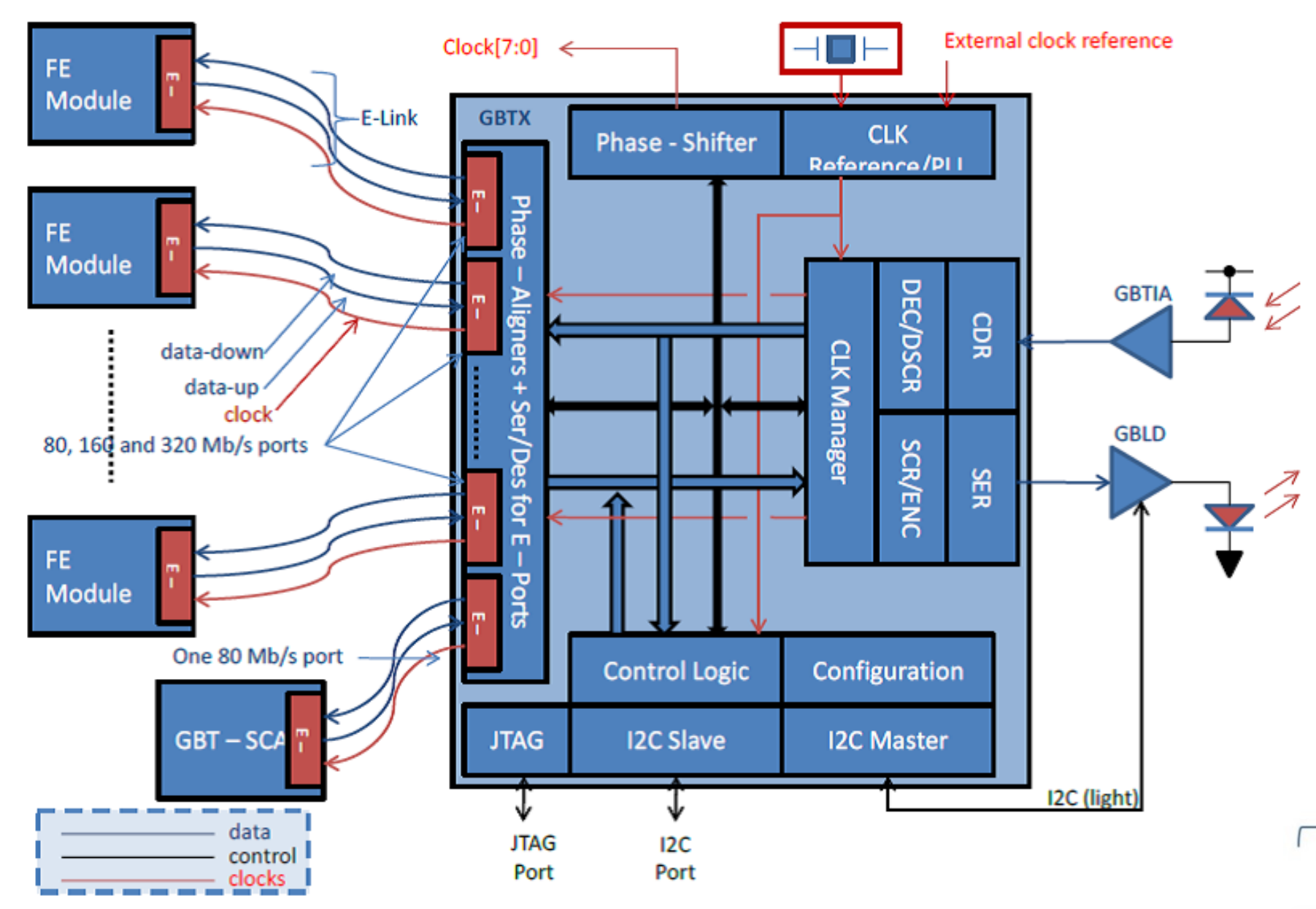

Figure taken from GBTX manual
- Radiation tolerant ASIC

- $1 \mathrm{E}$-Link is 3 differential pairs

- $\operatorname{Clock}(40,80,160$ or $320 \mathrm{MHz})$

- data-up (monitoring data - Level-1 data)

- data-down (configuration data)

- E-Links can be grouped in 5 independent banks that can support

-40 E-Links@80 Mbps

- 20 E-Links @ 160 Mbps

- 10 E-Links @ 320 Mbps

- Different E-Link configuration for each detector

- MMs: 8 FEs/L1DDC

- $\quad$ sTGC: 3 FEs/L1DDC

- Clock and data-down have the same phase

- Data-up are aligned to the GBTX clock

- Fiber side: $4.8 \mathrm{Gbps}$ transmitting speed

- GBTX is configured by the Internal Control (IC) channel

- GBTX logic uses Triple Modular Redundancy (TMR) 120 bits

\begin{tabular}{|c|c|c|c|c|c|c|c|c|c|}
\hline$\Gamma$ & $\begin{array}{l}\text { Internal } \\
\text { Control }\end{array}$ & $\begin{array}{l}\text { External } \\
\text { Control }\end{array}$ & & & & & & & \\
\hline $\begin{array}{l}\text { Header } \\
(3: 0)\end{array}$ & IC (1:0) & EC (1:0) & $\begin{array}{c}\text { Data } \\
(47: 64)\end{array}$ & $\begin{array}{c}\text { Data } \\
(63: 48)\end{array}$ & $\begin{array}{c}\text { Data } \\
(47: 32)\end{array}$ & $\begin{array}{c}\text { Data } \\
(31: 16)\end{array}$ & $\begin{array}{c}\text { Data } \\
(15: 0)\end{array}$ & \begin{tabular}{|c|} 
FEC \\
$(31: 16)$
\end{tabular} & $\begin{array}{c}\text { FEC } \\
(15: 0)\end{array}$ \\
\hline $\begin{array}{c}\text { Header fiel } \\
\text { - 4bits }\end{array}$ & $\begin{array}{l}\text { Slow } \\
\text { field }\end{array}$ & $\begin{array}{l}\text { ontrol } \\
4 \text { bits }\end{array}$ & & & field - 8 & & & $\begin{array}{l}\text { Forwa } \\
\text { orrection }\end{array}$ & $\begin{array}{l}\text { d Error } \\
\text { ield - 32bits }\end{array}$ \\
\hline
\end{tabular}




\section{GBT-SCA}

- Is used for monitoring and configuration purposes

- Uses the SLVS standard

- 1 + 1 auxiliary E-Link @ 80 Mbps

- 8 x SPI master

- JTAG

- $16 \times I^{2} \mathrm{C}$

- 31 x Analog inputs

- 32 general purpose IOs

- 4 analogue outputs

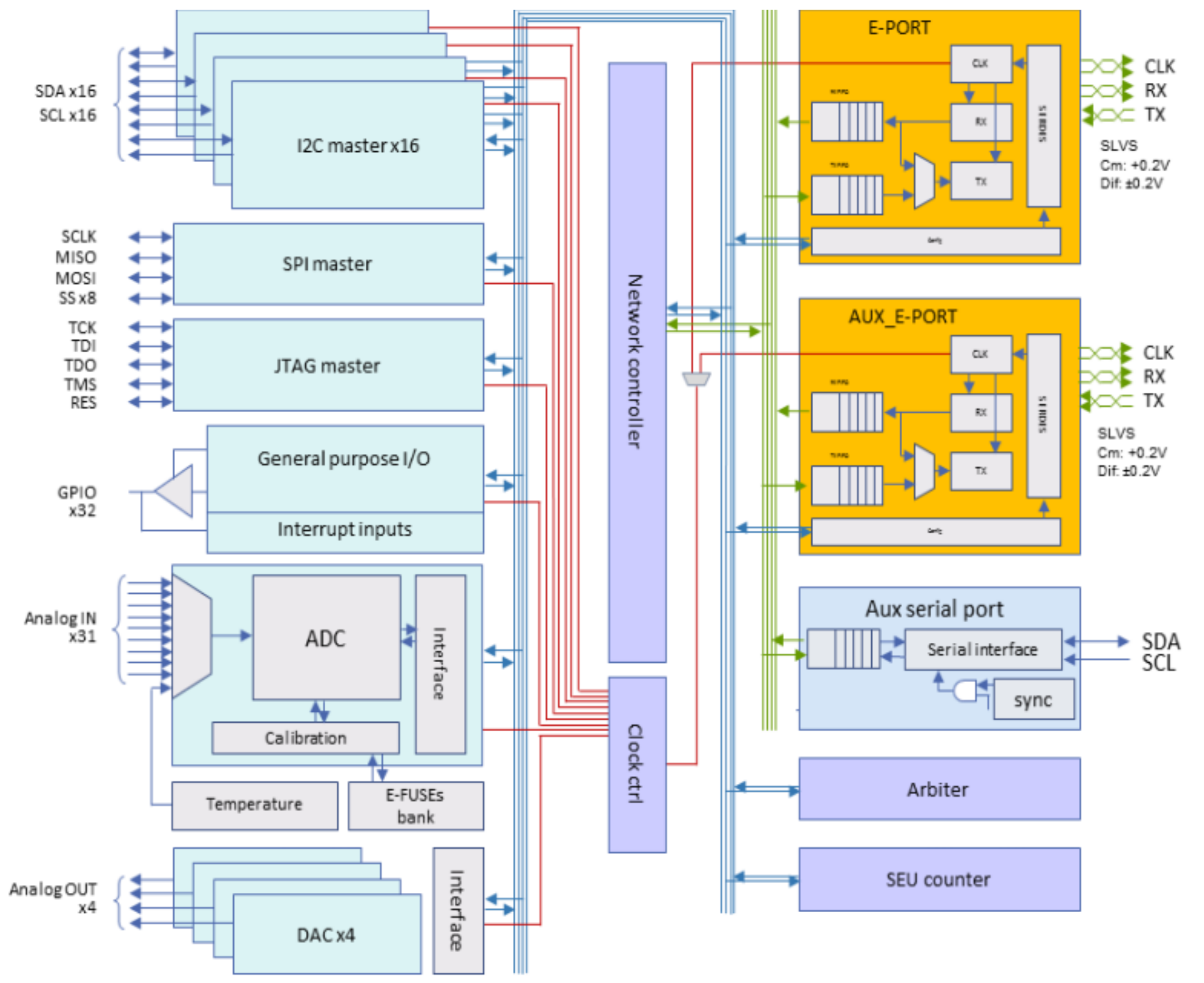




\section{Level-0 \& level-1 options}

- IDR single level: $1 \mathrm{MHz}$ Level-0 accept with full detector readout, EFTrack, FTK++ and Event Filter

- IDR dual level: $1 \mathrm{MHz}$ Level-0 accept, $400 \mathrm{kHz}$ Level-1 accept (main rate reduction from L1Track), FTK++ and Event Filter

- "Low latency dual level": $4 \mathrm{MHz}$ Level-0 accept, 600 kHz Level-1 accept (main rate reduction from L1Track), FTK++ and Event Filter 


\section{Overall scheme}

Rim electronics -10 boards

- 8 Routers

- 1 PAD trigger

- 1 RIM-GBT

\section{sTGC fibre plan - one sector}

to Sector Logic
(up to 14 fibres)

512 bi-dir GBT links

1024 uni-dir trigger llinks
Use of 6 spare pairs configuration

to FELIX
24 pairs

wating $25 \%$ of the FELIX ports is to cut a bad fibre and re-weld a spare G

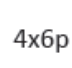

Readout: splitter: trunk-to-12-fiber in USA15: in: $4 \times 12$ fibres from trunk; out: $4 \times 6$-pair patches

USA-15 E $4 \times 12$ fibres on trunk Cavern

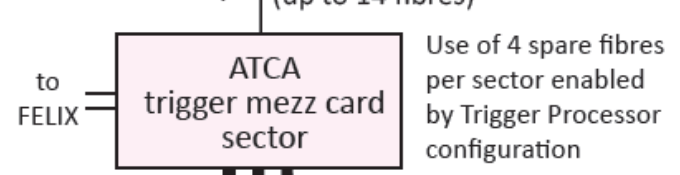

$3 \times 12 f$
The trigger card receives only 34 of its 36 inputs from the Front end. The other two come from FELIX.

The letter indicators refer to details in FibrePlan_V3.xlsx

Trigger: splitter: trunk-to-12-fiber in USA11: Trigger: splitter: trunk-to-12-fiber in USA15:
in: 3×12-fibres from trunk; out: 3×12-fibre patchs.

M 3x12 fibres on trunk

Trunk cables are multiples of 12 fibres Low-laten

tence and may serve more than one sector.

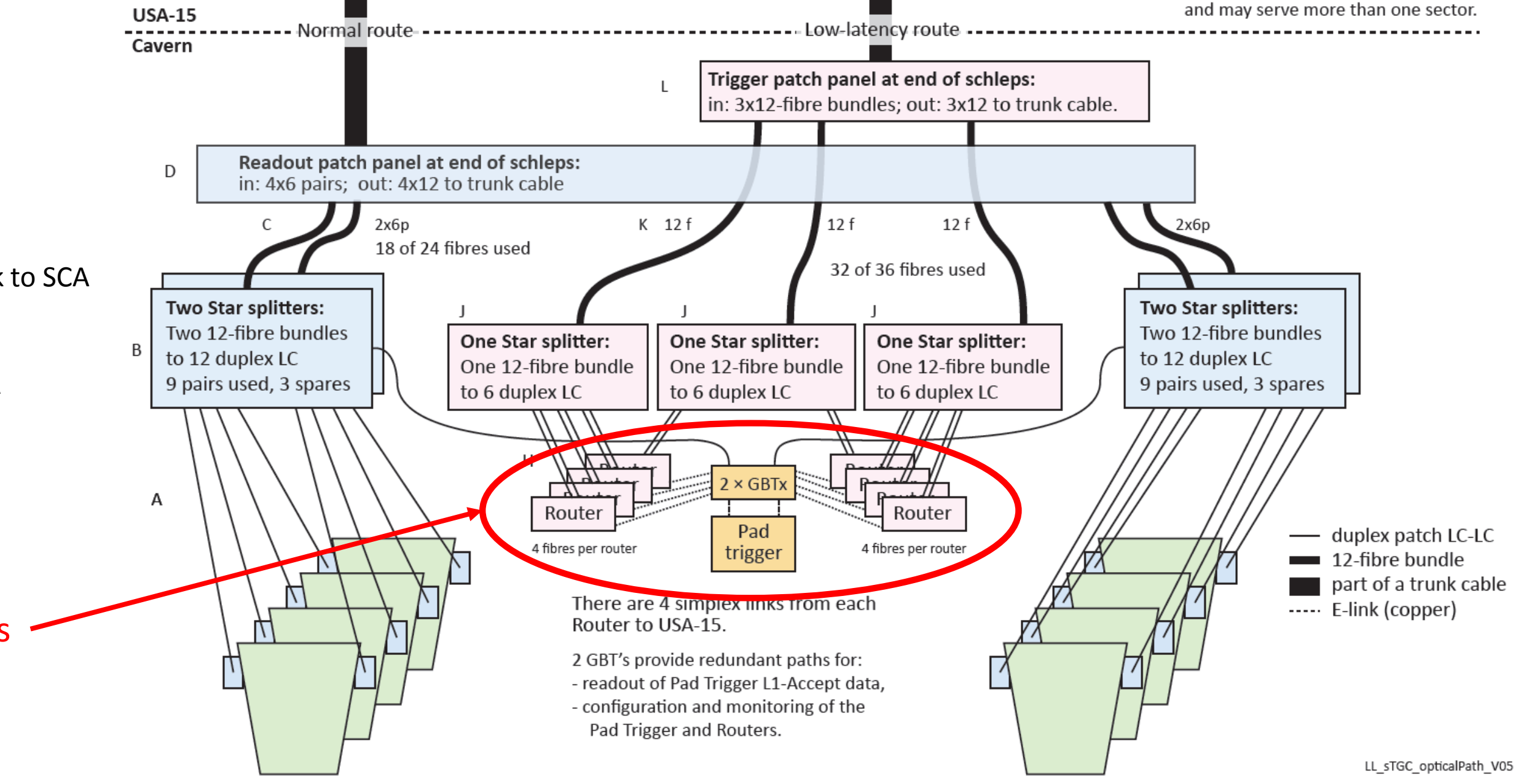

\section{RIM boards}

\section{RIM-GBT}

\section{- Transmits}

- configuration data and clock to SCA

- BC clock to FPGA

- Configuration data to FPGA

- Any additional data to FPGA

Receives

- monitoring data from SCAs

- Data from the FPGA 


\section{MMs detector}

MMs PCB layout

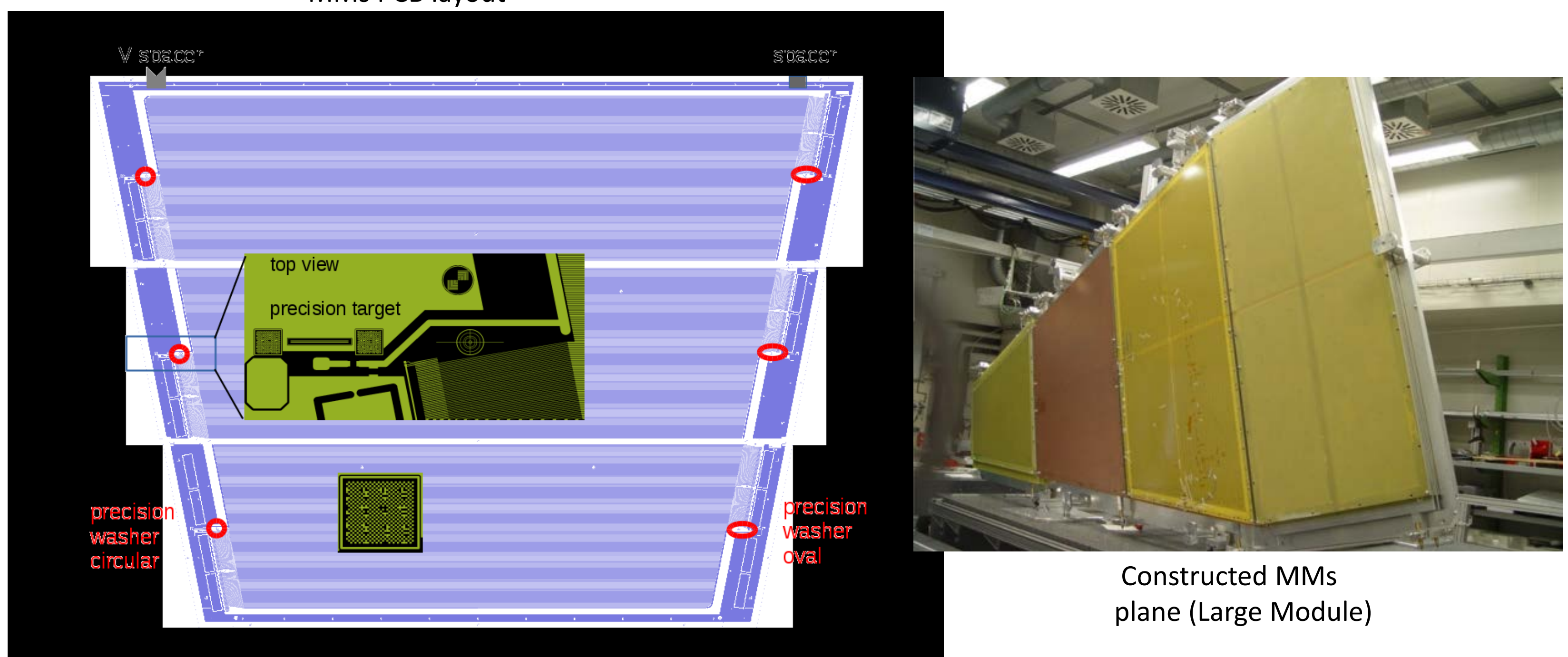




\section{RIM-L1DDC}

- Transmits the TTC data to the trigger boards (Pad and Router)

- Receives monitoring and any additional data from the trigger boards

- Fully redundant board

- 2 GBTX ASICs

- 2 VTRX optical transceivers

- 18 miniSAS vertical connectors

- $8+8$ for redundancy for Routers

- $1+1$ for redundancy for Pads

- 2 voltage levels

- $1.5 \mathrm{~V}$ for GBTX ASICs

- $2.5 \mathrm{~V}$ for VTRX transceivers

- 4 FEASTs (2 for redundancy)

- GBTX standards

- SLVS for the Tx

- LVDS and SLVS for Rx

- Power consumption 11 Watts

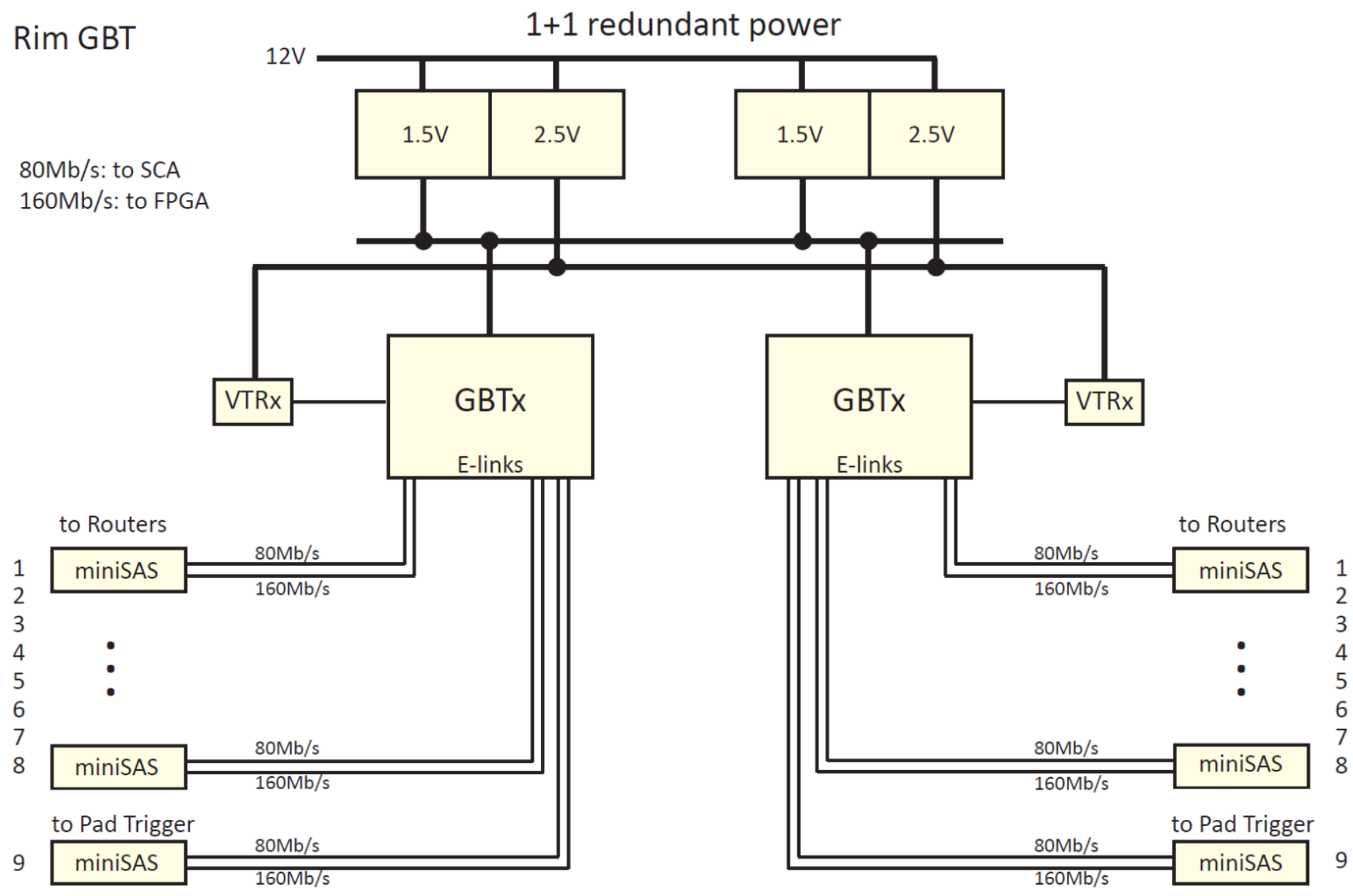

